\title{
Evaluation and Treatment of Posterior Neck Pain in Family Practice
}

\author{
Alan B. Douglass, MD, and Edward T. Bope, MD
}

Neck pain is almost universal and is a common patient complaint. Although the differential diagnosis is extensive, most symptoms are from biomechanical sources, such as axial neck pain, whiplash-associated disorder (WAD), and radiculopathy. Most symptoms abate quickly with little intervention. There is relatively little high-quality treatment evidence available, and no consensus on management of axial neck pain or radiculopathy. A number of general pain management guidelines are applicable to neck pain, and specific guidelines are available on the management of WAD. The goal of diagnosis is to identify the anatomic pain generator(s). Patient history and examination are important in distinguishing potential causes and identifying red flags. Diagnostic imaging should be ordered only when necessary because of the high incidence of asymptomatic radiographic abnormalities. First-line drug treatments include acetaminophen, cyclo-oxygenase 2-specific inhibitors, or nonsteroidal anti-inflammatory drugs. Short-term use of muscle relaxants may be considered. Opioids should be used if other treatments are ineffective and continued if improved function outweighs impairment. Adjuvant antidepressants and anticonvulsants should be considered in chronic or neuropathic pain and coincident depression. Epidural steroids should be considered only in radiculopathy. Physical modalities supported by evidence should be used. If symptoms have not resolved in 4 to 6 weeks, re-evaluation and additional workup should be considered. (J Am Board Fam Pract 2004;17:S13-22.)

The human neck is a complex structure that is highly susceptible to irritation. In fact, $10 \%$ of people will have neck pain in any given month. ${ }^{1}$ Potential pain generators include bones, muscles, ligaments, facet joints, and intervertebral discs (Figure 1). Almost any injury or disease process within the neck or adjacent structures will result in reflexive protective muscle spasm and loss of motion. Gradual collapse of the intervertebral discs and degeneration of the facet joints is a universal part of the aging process and, in some people, can lead to nerve or spinal cord impingement. Further, neck mobility is so important to normal human

From the Family Practice Residency Program, Middlesex Hospital, Middletown, CT (ABD), and Riverside Family Practice Residency Program, Riverside Methodist Hospital, Columbus, $\mathrm{OH}$ (ETB). Address correspondence to Alan B. Douglass, MD, FAAFP, Family Practice Residency Program, Middlesex Hospital, 90 South Main Street, Middletown, CT 06457 (e-mail: alan_douglass_md@midhosp.org).

The Family Practice Pain Education Project (FP-PEP) acknowledges an unrestricted educational grant from Pfizer to Cardinal Health to produce educational materials for primary care doctors about pain management. The information provided here is the opinions and research of the family physicians who served on FP-PEP.

This work was presented in part at the 2003 American Academy of Family Physicians (AAFP) Scientific Symposium. functioning that any disruption in its normal function is quickly noticed.

\section{Differential Diagnosis}

Neck pain has an extensive differential diagnosis (Table 1). By far, the most common causes are biomechanical: axial neck pain, whiplash-associated disorder (WAD), and cervical radiculopathy. Much less common causes include cervical myelopathy caused by spinal cord compression, infection, neoplasms, rheumatic causes (ankylosing spondylitis, spondyloarthropathies, rheumatoid arthritis, and diffuse idiopathic skeletal hyperostosis), torticollis, cervical dystonia, and major trauma, including fractures, dislocations, and cord injuries. Pain also may be referred to the neck from other sources, such as shoulder disorders, thoracic outlet syndrome, esophagitis, angina, and vascular dissection. Neck pain may also present as part of complex generalized pain syndromes such as fibromyalgia.

\section{Definitions}

This article focuses on the 3 most common sources of neck pain that are encountered by primary care physicians: axial neck pain, WAD, and cervical radiculopathy. Cervical myelopathy is briefly dis- 

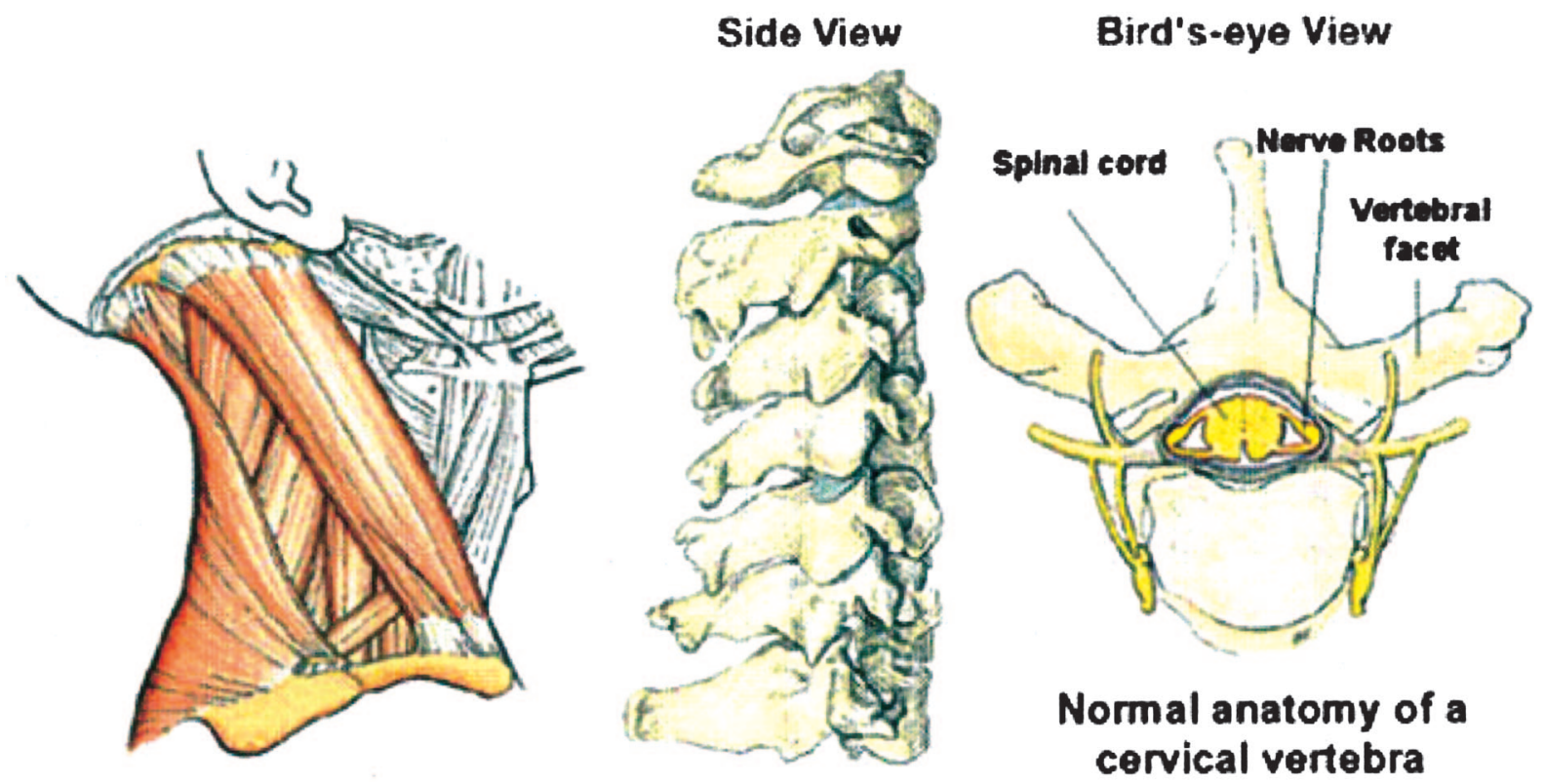

Figure 1. Normal neck anatomy.

cussed as well because of its importance in the differential diagnosis of neck pain.

Axial neck pain (also known as uncomplicated neck pain and cervical strain) is the result of the complex interaction of muscular and ligamentous factors related to posture, sleep habits, ergonomics such as computer monitor and bifocal position, stress, chronic muscle fatigue, postural adaptation to other primary pain sources (shoulder, temporomandibular joint, craniocervical), or degenerative changes of the cervical discs or facet joints. The ICD-9 code is 723.1 .

\section{Table 1. Differential Diagnosis of Neck Pain}

\begin{tabular}{l}
\hline Biomechanical causes \\
Axial neck pain \\
Whiplash associated disorder (WAD) \\
Radiculopathy \\
Cervical myelopathy \\
Infection \\
Neoplasm \\
Rheumatic causes \\
Rheumatoid arthritis \\
Ankylosing spondylitis \\
Spondyloarthropathies \\
Diffuse idiopathic skeletal hyperostosis \\
Dystonia \\
Trauma \\
Torticollis \\
Referred pain \\
Fibromyalgia \\
\hline
\end{tabular}

Whiplash-associated disorder (WAD) is a special case of acute or subacute neck pain resulting from acceleration/deceleration transfer of energy to the neck. Multiple pain generators are usually involved, including myofascial, ligamentous, discogenic, and facet joint sources. It most commonly occurs in rear-end motor vehicle crashes, but can occur from other causes, such as diving injuries. The Quebec Classification of Whiplash-Associated Disorders identifies 4 categories of injury ${ }^{2}$ : grade I comprises general, nonspecific complaints regarding the neck, such as pain, stiffness, or soreness without objective physical findings; grade II comprises neck complaints plus signs limited to musculoskeletal structures; grade III comprises neck complaints plus neurologic signs; and grade IV comprises neck pain plus fracture or dislocation and is beyond the scope of this paper. All subsequent discussion of WAD assumes that fracture, subluxation, and cord injury have been ruled out. The ICD-9 code is 847.0

Cervical radiculopathy is motor and/or sensory changes in the neck and arms resulting from extrinsic pressure on a cervical nerve root, usually by osteophytes or disk material. The pathology underlying the symptoms is heterogeneous. Seventy to ninety percent of cases are associated with foraminal encroachment by degenerative bony changes; herniated disk material is present in most of the remainder. ${ }^{3}$ An inflammatory response is probably necessary for the initiation of symptoms. ${ }^{4}$ The ICD-9 code is 723.4. 
Myelopathy is the manifestation of long tract signs resulting from a decrease in the space available in the cervical canal for the spinal cord. A number of factors contribute to extrinsic pressure, including the congenital cord diameter, osteophytes, protruding disk material, dynamic changes in canal diameter and the cord itself, and the vascular supply to the cord. ${ }^{4}$ The ICD-9 code is 721.1 .

\section{Prevalence and Natural History}

Neck pain is an extremely common but nonspecific symptom. In a population-specific study, Cote et al found that $66 \%$ of Saskatchewan adults experienced neck pain at some point in their lifetimes, $54 \%$ in the most recent 6 months. ${ }^{5}$ The prevalence of neck pain at any point in time is approximately $9 \% .{ }^{1}$ Prevalence increases with age and is higher in women than in men. ${ }^{6}$ Neck pain accounts for almost $1 \%$ of all visits to primary care physicians in the United States. ${ }^{7}$

Axial neck pain is the most common cause of neck pain and has a high rate of spontaneous resolution. In one study, after 3 months of nonoperative care, $70 \%$ had complete or partial relief. ${ }^{8}$ With time, most patients achieve relief. In another study, at the 10- to 25 -year follow-up, $43 \%$ experienced complete resolution, $25 \%$ mild residual pain, and $32 \%$ moderate or severe residual pain. ${ }^{9}$

In the United States, 1 million cases of WAD occur annually as a result of motor vehicle accidents. ${ }^{10}$ Prognostic data are variable, but in one large study, $60 \%$ of patient symptoms resolved within 1 month. ${ }^{11}$ The incidence of chronic symptoms after acute WAD varies widely among cultures and countries, ${ }^{2}$ and lively medical debate is ongoing about the diagnosis of chronic WAD. ${ }^{12,13}$ There is sparse evidence for a causal link between the mechanism of WAD injury and chronic symptoms. ${ }^{14}$ Some authors feel that the symptoms of WAD are often reinforced by legal and social factors. ${ }^{13}$ It is interesting that in Lithuania, where there is little involvement of insurance companies or the legal system in motor vehicle injuries, no difference was found in persistent neck symptoms between rear-end-crash victims and uninjured controls. ${ }^{15}$ Nonetheless, in 11 high-quality studies, $19 \%$ to $60 \%$ (mean, $33 \%$ ) of patients with WAD reported chronic symptoms. ${ }^{16}$ Overall, $7 \%$ of people who are asymptomatic 3 months after an accident will have symptoms after 2 years. On the other hand, $85 \%$ of people who are symptomatic 3 months after an accident will remain so after 2 years. $^{17}$

A large, population-based study in Rochester, Minnesota, noted the annual incidence of cervical radicular symptoms to be 83.2 per 100,000 population, peaking in the 50- to 54-year age-group. ${ }^{3}$ Many patients will have resolution of symptoms without surgery. In the Rochester study at a mean follow-up of 5.9 years, $90 \%$ of patients were asymptomatic or only mildly incapacitated. Referral center-based studies have shown somewhat less positive outcomes.

The overall prevalence of cervical myelopathy is unknown, but it is relatively rare and the natural history of the disorder in any one person is unpredictable. However, a number of studies have documented progressive deterioration without surgery. ${ }^{4}$ In one recent study of patients who underwent laminectomy and posterior fusion, $80 \%$ had good outcomes, $76 \%$ had improvement in myelopathy scores, and no late neurological deterioration in any group was documented at mean follow-up of 4 years. ${ }^{18}$

\section{Presenting Symptoms}

Axial neck pain and WAD typically present as pain or soreness in the posterior paramedian neck muscles, with radiation to the occiput, shoulder, or parascapular region. Stiffness in one or more directions of motion and headache are common. Axial neck pain and WAD can be associated with local warmth or tingling. Localized areas of muscle tenderness (trigger points) may develop.

Radicular pain is sharp, tingling, or burning in a specific dermatomal distribution in the upper extremity. In clinical practice it is often confused with radiating pain. However, because there are specific treatments indicated only for radicular pain, an accurate distinction must be made. True radicular pain follows dermatomal patterns (Figure 2) which can be somewhat variable among patients and is usually, but not always, unilateral. Onset is often insidious but may be abrupt. It is frequently aggravated by arm position and extension or lateral rotation of the head. In one study of 736 patients, $99 \%$ had arm pain, $85 \%$ had sensory deficits, $79 \%$ had neck pain, $71 \%$ had reflex deficits, $68 \%$ had motor deficits, and $52 \%$ had scapular pain. ${ }^{19}$

Cervical myelopathy has a subtle and varied presentation necessitating a high degree of clinical 


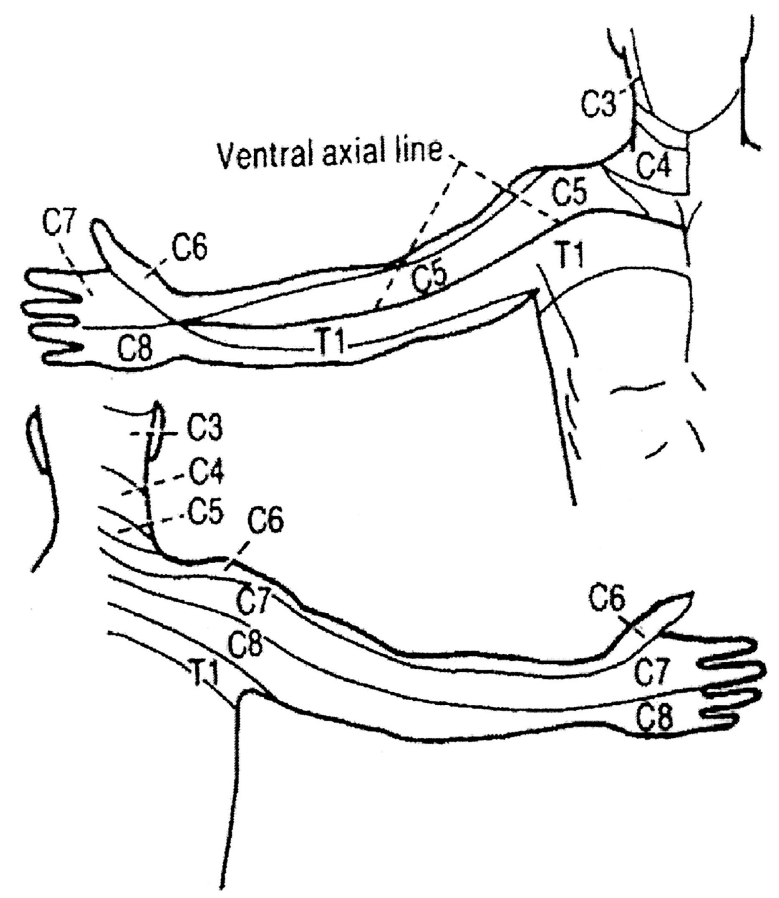

Figure 2. Dermatomal pattern of radicular pain.

suspicion. Patients may present with subtle findings that have been present for years, or with acute paresis. They typically complain of insidious clumsiness, weakness, or stiffness in the upper and lower extremities. Deep, aching pain in the neck, shoulder, or arm and neck stiffness are common but occur in less than half of patients. Associated radicular symptoms occur in one third of patients. Arm or leg dysfunction and gait and balance difficulties are common. Nonspecific urinary complaints, such as urgency or hesitancy, can occur, but frank urinary or fecal incontinence is unusual. ${ }^{4,20}$

\section{Current Standards of Care}

Currently available guidelines specific to neck pain include the Quebec (Canada), ${ }^{2}$ and New South Wales (Australia) ${ }^{21}$ WAD Guidelines; Prodigy Guidance on Neck Pain (United Kingdom) ${ }^{22}$; and the Philadelphia Panel guidelines on rehabilitation interventions (United States). ${ }^{23}$ A number of general pain diagnostic and management guidelines applicable to neck pain are also available, including those from the American Geriatrics Society, ${ }^{24}$ the American Academy of Physical Medicine and Rehabilitation, ${ }^{25}$ the American Pain Society, ${ }^{26}$ the American College of Rheumatology, ${ }^{27}$ and the American Society of Anesthesiologists. ${ }^{28}$
Despite the availability of guidelines, there is no clear consensus on the management of axial neck pain or radiculopathy. Clinicians commonly use multiple medications and modalities empirically, often without clear evidence supporting their efficacy.

\section{Evaluation of Patients With Neck Pain History and Physical Examination}

A careful history can yield a diagnosis, or at least categorization of symptoms, in the majority of patients. History should focus on the mechanism of injury (if any) and on symptoms. Any prior neck trauma or symptoms should be noted. Clinicians should be alert for a number of red flags for potentially serious conditions requiring prompt diagnosis and management. Morning stiffness that improves over the course of the day is sometimes indicative of rheumatic causes. Fever, weight loss, night sweats, and other systemic symptoms are indicative of infection or neoplasm. Unremitting night pain, especially in the context of a prior history of malignancy, may be secondary to a bony tumor. Gait disturbance, balance problems, sphincter dysfunction, or loss of coordination suggests myelopathy. Patients should be carefully questioned about past treatment successes and failures.

A careful physical examination is vital for differentiating potential causes. Inspection should focus on posture, ease of movement, and visible deformities. Palpation of soft tissue and bony and other cervical structures such as thyroid, lymph nodes, and salivary glands should be performed. Cervical range of motion in flexion, extension, lateral bending, and rotation should be noted, along with shoulder range of motion. Neurologic examination of sensory and motor function as well as reflexes is vital. Several special maneuvers can be helpful. Axial loading of the neck while the head is extended and rotated (Spurling maneuver) will often provoke radicular pain. Placing the affected hand on top of the head (abduction relief sign) takes stretch off of the affected nerve root and may decrease or relieve radicular symptoms. An electric shock sensation down the center of the back after neck flexion (Lhermitte sign) is indicative of cervical spinal cord pathology such as cervical myelopathy.

\section{Diagnostic Imaging}

Diagnostic imaging in neck pain can be misleading, in that it frequently identifies abnormalities that are 


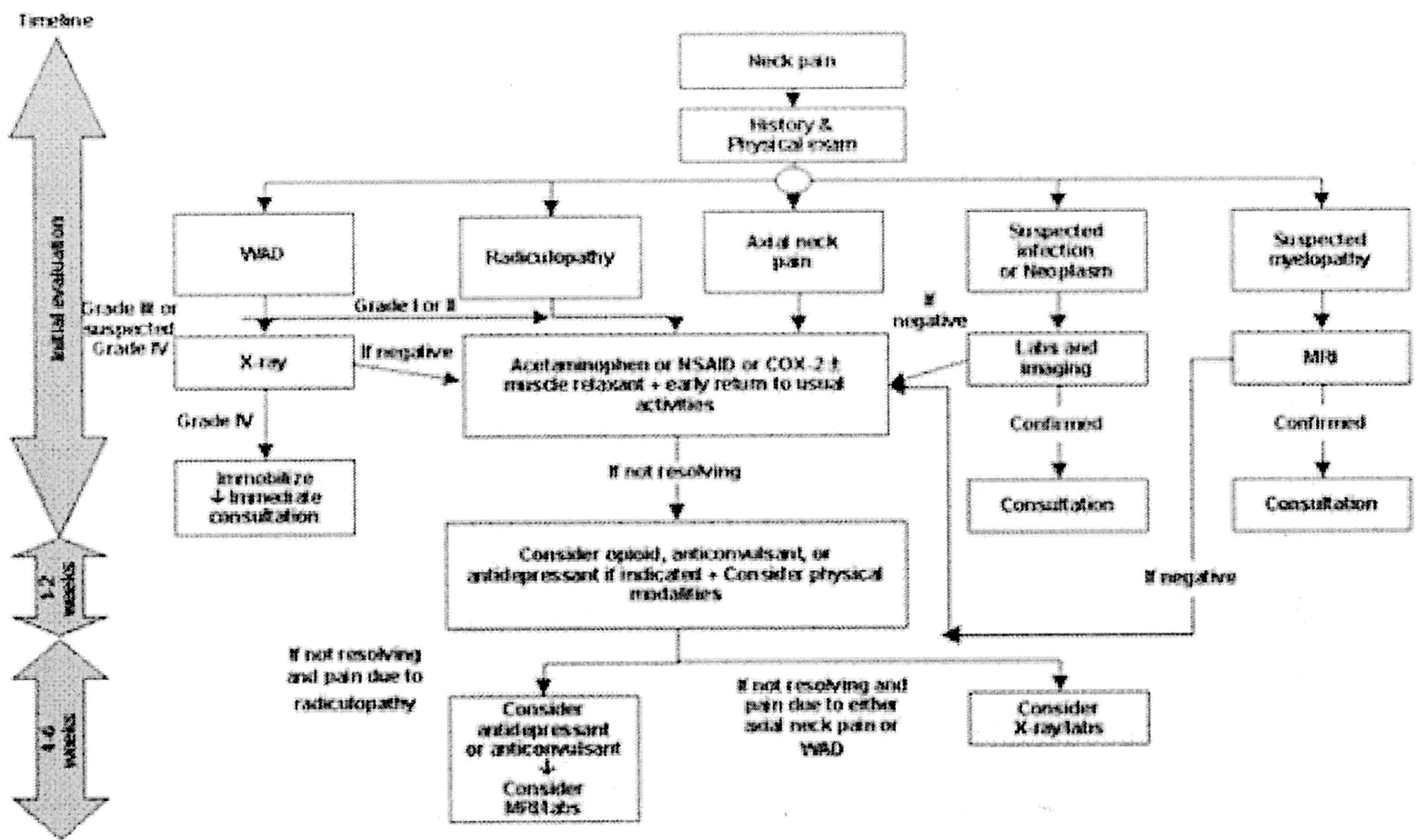

Figure 3. Algorithm for the management of patients with neck pain.

not contributory to current symptoms. One study of radiographs of asymptomatic persons between 50 and 65 years of age demonstrated that $79 \%$ of subjects had disk space narrowing, endplate sclerosis, or osteophytes. ${ }^{29}$ Another study of magnetic resonance images revealed major abnormalities, such as bulging or herniated discs, foraminal stenosis, disk space narrowing, or abnormal cord signal in $14 \%$ of asymptomatic subjects younger than 40 years and in $28 \%$ older than 40 years. ${ }^{30}$

Radiographs are recommended in patients with WAD grade III or suspected grade IV (grade IV cannot be diagnosed without an radiograph) and in patients with a history of trauma (recommendation strength A). Detailed guidelines for radiograph selection in patients with blunt neck trauma are available, including the Canadian C-spine rule, NEXUS decision instruments, and American College of Radiology Appropriateness Criteria. ${ }^{31-33}$ Plain radiographs also should be considered in patients with axial neck pain unresponsive to 6 to 8 weeks of conservative treatment; however, no clear guidelines are available. Magnetic resonance imaging should be performed if myelopathy, infection, or neoplasm is suspected; in patients with radicular pain associated with motor or reflex deficits; and in patients with radicular symptoms that have not resolved in 6 to 8 weeks (recommendation strength B). ${ }^{34}$

\section{Management of the Patient With Neck Pain}

Figure 3 displays an algorithmic approach to the management of patients with neck pain. The history and physical examination serve as a triage point to divide patients into 5 categories based on the suspected cause of their symptoms. The following section reviews the evidence underlying the management recommendations for each category laid out in the algorithm.

\section{Review of the Evidence}

In the management of neck pain, clinical practice has far outpaced the literature supporting what is commonly done. There is relatively little highquality evidence specific to the treatment of neck pain. In fact, there are almost as many reviews as there are controlled trials of therapies; for many interventions, there is no concordance in the conclusions drawn by reviewers. Few studies have been made of the long-term effects of treatments for neck pain. 


\section{Drug Therapies}

Because of a paucity of high-quality studies of drug therapy specific to neck pain, much of the following information has been extrapolated from the treatment of pain from other causes, largely low back pain.

\section{Acetaminophen}

The use of full-dose (2 to $4 \mathrm{~g}$ per day) acetaminophen as a first-line therapy is supported by strong evidence and several major sets of guidelines (recommendation strength A). ${ }^{24,26}$ It should be recognized that in alcoholism, fasting states, hepatic disease, the presence of certain medications (especially anticonvulsants), or in the frail elderly, liver toxicity can occur at recommended doses. ${ }^{35}$ Furthermore, acetaminophen toxicity increases substantially when it is taken in conjunction with a cyclo-oxygenase (COX-2)-specific inhibitor or nonsteroidal anti-inflammatory drug (NSAID). ${ }^{36}$

\section{NSAIDs}

There is strong evidence of efficacy in acute pain and moderate evidence in chronic pain (recommendation strength A). NSAIDs are recommended by most major sets of guidelines. The efficacy of all NSAIDs seems to be roughly equivalent. ${ }^{37}$ Weighing efficacy versus adverse effects, the American Geriatrics Society recommends COX-2 inhibitors as first-line therapy over traditional NSAIDs. ${ }^{24}$ Nonacetylated salicylates (choline magnesium trisalicylate, salsalate) are effective and may have fewer gastrointestinal side effects than traditional NSAIDs at a lower cost than more selective agents. ${ }^{24,26}$ If traditional NSAIDs are chosen, gastric cytoprotection should be considered based on the patient's risk profile. NSAIDs should be particularly considered when inflammation is believed to be playing a substantial role in the production of the pain process.

\section{Muscle Relaxants}

Evidence supporting the use of muscle relaxants is mixed (evidence strength B). A review of 14 moderate-quality randomized, controlled trials showed that cyclobenzaprine was more effective than placebo in the management of neck and back pain. However, the effect was modest and came at the price of greater adverse effects. The effect was greatest in the first 4 days of therapy. ${ }^{38}$ Similar conclusions have been reached for other drugs in this class. ${ }^{37}$ Baclofen and tizanidine may have less potential for addiction than other muscle relaxants. Muscle relaxants are not recommended for acute phase WAD because of limited evidence of efficacy. $^{2,21}$

\section{Opioids}

An extensive body of literature documents the short-term effectiveness of opioids in a variety of pain syndromes (recommendation strength A). However, no high-quality, randomized, controlled trials of sufficient length exist to demonstrate longterm efficacy and safety for any indication. ${ }^{25}$ The usefulness of opioids in neck pain must be balanced against adverse effects such as constipation, sedation, and physiologic dependence. Several major recommending bodies support the use of opioids in a variety of pain syndromes when other strategies do not provide adequate pain relief, and there is clear evidence that they do not impair the patient and produce significant and sustained improvement. ${ }^{25,28}$

\section{Adjuvant Antidepressants and Anticonvulsants}

Although there are no good quality randomized, controlled trials of the use of these agents specifically in neck pain, their use, especially in chronic and neuropathic pain, is widely supported by the literature (recommendation strength A) and all major sets of general pain management guidelines. ${ }^{24-26,28}$ It should also be noted that in chronic pain syndromes, coincident depression is frequent, and aggressive treatment of depression can often be of benefit.

\section{Sedative Hypnotics}

No high-quality randomized, controlled trials of sufficient length exist to demonstrate long-term efficacy and safety in any pain syndrome. ${ }^{25}$ Other than relieving pain specifically caused by muscle spasm, they are otherwise not effective analgesics. ${ }^{26}$

\section{Trigger Point Injections}

Although widely used, evidence of efficacy is currently lacking. ${ }^{25,37} \mathrm{~A}$ single randomized trial, albeit for low back pain, showed no difference in pain response between saline injection, anesthetic injection, needle insertion without injection, and vapocoolant spray with acupressure. ${ }^{39}$ 
Steroids

Epidural injection of steroids is a commonly performed procedure for radicular neck and lower back pain. Trial results are roughly divided between positive and negative results ${ }^{37}$ Variability in response may be a result, at least in part, of heterogeneous pathology in this group of patients and differences in technique. Recent trials with more careful patient selection and standardized techniques have shown more positive results. The decision to consider epidural steroids in any given patient is therefore an exercise in clinical judgment. There exists no clear rationale for epidural steroid injection in nonradicular pain. Their use should be reserved for clear radicular pain (recommendation strength B). ${ }^{37,40}$ Some recommending bodies support the use of epidural steroid injections, ${ }^{28}$ whereas others do not. ${ }^{25}$ Small trials of the clinical efficacy of systemic steroids have been inconclusive, ${ }^{37}$ and clinical trials comparing oral and epidural steroids have not been performed. Intraarticular injection of steroids has not been shown to provide effective long-term pain relief, ${ }^{37,41}$ and they are not recommended in chronic WAD. ${ }^{2,21}$

\section{Percutaneous Radio Frequency Neurotomy}

One randomized controlled trail in patients with chronic WAD-related neck pain demonstrated a significant increase in the number of patients who were pain-free at 27 weeks after percutaneous radio frequency neurotomy of the facet joints compared with sham procedure. In those patients who were not pain-free, the median time to return to $50 \%$ of the preoperative level of pain was markedly longer in the treatment group. ${ }^{42}$ This technique is currently available only in research centers.

\section{Physical Modalities Likely to be Beneficial}

The use of the following physical modalities is supported by a reasonable quantity of high-quality scientific evidence (recommendation strength B).

\section{Early Return to Usual Activities}

Good evidence supports its recommendation in WAD. ${ }^{2,21,43}$

\section{Supervised Exercise}

Good evidence of positive effect on acute traumatic neck injuries ${ }^{44}$ and clinically important benefit on pain and function in chronic neck pain have been reported..$^{23,26}$ Exercise is recommended in WAD. ${ }^{2,21}$

\section{Manipulation and Mobilization}

Manipulation of the spine directs a high-velocity thrust at one or more joints of the cervical spine. Mobilization includes all manual therapies directed at cervical joint dysfunction that do not involve high-velocity thrusts. Both modalities probably provide at least short-term benefit in patients with neck pain, but more high-quality research is needed before definitive recommendations can be made. ${ }^{43,45,46}$ Both manipulation and mobilization are recommended in grades II and III WAD. ${ }^{2}$

\section{Pulsed Electromagnetic Field Therapy}

Significant reductions in pain and increases in cervical range of motion in studies of high methodologic quality were found in 4 reviews. ${ }^{43,44,46,47}$

\section{Physical Modalities With No Evidence of Effect}

The following physical modalities may be helpful in individual patients, but their use is not currently supported by a reasonable quantity of high-quality scientific evidence.

\section{Thermotherapy}

Systematic reviews found no demonstrated benefit for neck pain. ${ }^{23,43}$

\section{Immobilization}

Cervical collars have little effect on cervical range of motion in healthy adults. Inconclusive or no evidence of benefit in neck pain was found in 3 reviews. ${ }^{43,44,47}$ The New South Wales WAD guidelines recommended the use of soft collars for no more than 3 days in grades II and III WAD, ${ }^{21}$ whereas the Quebec guidelines do not recommended them and state that they should be discouraged. Their use beyond 72 hours probably prolongs disability. ${ }^{2}$

\section{Transcutaneous Electrical Nerve Stimulation}

Good-quality studies show no evidence of effect. $^{2,23}$

\section{Therapeutic Ultrasound}

Good-quality evidence shows no benefit. ${ }^{2,23}$ 
Educational Advice on Posture

One review found positive effect on acute traumatic neck injuries, ${ }^{44}$ but 2 others found insufficient evidence to make a recommendation. ${ }^{2,43}$

\section{Traction}

Available high-quality studies do not allow clear conclusions about the effectiveness of cervical traction. ${ }^{46-48}$ No major recommending body has found convincing evidence of positive effect for traction in either acute or chronic neck pain, and none recommends it. ${ }^{2,23}$

\section{Acupuncture}

No reviews show clear demonstration of effectiveness. A review of the outcomes of 14 randomized, controlled trials were equally balanced between positive and negative outcomes. ${ }^{6}$ Another review found high methodologic quality of studies, but interventions had either no effect or negative effect. ${ }^{46}$ Acupuncture treatment is not currently recommended for any form of neck pain by any major recommending body. ${ }^{2,25}$

\section{Conclusions}

Neck pain is an almost universal human condition and is among the most common complaints presented to family physicians. Although the differential diagnosis of neck pain is extensive, most symptoms are produced by biomechanical sources, such as axial neck pain, WAD, and cervical radiculopathy. Most symptoms will abate in a timely fashion with little intervention.

There is relatively little high-quality evidence available that is specific to the treatment of neck pain, and there is a dearth of long-term outcomes data. This article presents a consensus on the management of axial neck pain and cervical radiculopathy. Straightforward guidelines are available on the management of WAD, and a number of general pain management guidelines that are applicable to neck pain are also available.

Patient history and physical examination are important in distinguishing potential etiologies and immediately identifying red flags for more serious conditions. Distinguishing between radicular and nonradicular neck pain is particularly important. Diagnostic imaging should be ordered only when truly necessary because of the high incidence of cervical radiographic abnormalities in asymptomatic persons.

Recommended first-line drug treatment should be with acetaminophen, COX-2-specific inhibitors, or NSAIDs. Short-term muscle relaxants may be considered, but their sedative properties and addictive potential must be taken into account. Opioids should be used if other treatments have been insufficiently effective and continued if there is evidence of improved function that outweighs any impairment caused by adverse effects. Adjuvant antidepressants and anticonvulsants should be considered, especially in chronic or neuropathic pain and when coincident depression is suspected. Epidural steroid injections should be considered only in cervical radiculopathy. Physical modalities supported by evidence of benefit should be used, including early return to usual activities, supervised exercise, electromagnetic therapy, manipulation, and mobilization. If symptoms have not resolved within 4- to 6-weeks, re-evaluation and additional diagnostic workup should be considered.

We acknowledge the contributions of the other members of the Family Practice Pain Education Project: Gail Cawkwell, MD, Alan Gibovsky, MD, Deborah Haynes, MD, Tanya Jones, MD, Laeth Nasir, MBBS, Trish Palmer, MD, Sunil Panchal, MD, Francine Rainone, MD, PhD, Peter Rives, MD, Knox Todd, MD, and James Toombs, MD.

\section{References}

1. Lawrence JS. Disc degeneration. Its frequency and relationship to symptoms. Ann Rheum Dis 1969 Mar;28:121-38

2. Quebec Task Force on Whiplash-associated disorders cohort study. Spine 1995;20 Suppl 8:125-65.

3. Radhakrishnan K, Litchy WJ, O'Fallon WM, Kurland LT. Epidemiology of cervical radiculopathy. A population-based study from Rochester, Minnesota, 1976-1990. Brain 1994;117:325-35.

4. Rao R. Neck pain, cervical radiculopathy, and cervical myelopathy: pathophysiology, natural history, and clinical evaluation. J Bone Joint Surg Am 2002; 84:1872-81.

5. Cote P, Cassidy J, Carroll L. The Saskatchewan health and back pain survey. The prevalence of neck pain and associated disability in Saskatchewan adults. Spine 1998;23:1689-98.

6. White AR, Ernst E. A systematic review of randomized controlled trials of acupuncture for neck pain. Rheumatology 1999;38:143-7.

7. Green LA, Phillips RL, Fryer, GE. The nature of primary medical vare. In: Jones $\mathrm{R}$, Britten $\mathrm{N}$, Culpepper L, Gass D, Grol R, Mont D, editors. 
Oxford textbook of primary medical care. London: Oxford University Press; 2003.

8. DePalma AF, Rothman RH, Liwinnek GE, Canale ST. Anterior interbody fusion for severe cervical disc degeneration. Surg Gynecol Obstet 1972;134: 755-8.

9. Gore DR, Sepic SB, Gardner GM, Murray MP. Neck pain: a long-term follow-up of 205 patients. Spine 1987;12:1-5.

10. Evans RW. Some observations of whiplash injuries. Neurol Clin 1992;10:975-97.

11. Ferrari R, Russell AS. Epidemiology of whiplash: an international dilemma. Ann Rheum Dis 1999; 58:1-5.

12. Hammacher ER, van der Werken C. Acute neck sprain: "whiplash" revisited. Injury 1996;27:463-66.

13. Pawl RP. Chronic neck syndromes: an update. Comp Ther 1999;25:278-82.

14. Stovner LJ. The nosologic status of the whiplash syndrome: a critical review based on a methodologic approach. Spine 1996;21:2735-46.

15. Schrader H, Obelieniene D, Bovim G, et al. Natural evolution of late whiplash syndrome outside the medicolegal context. Lancet 1996;347:1207-11.

16. Freeman MD, Croft AC, Rossignol AM. Whiplash associated disorders: redefining whiplash and its management, by the Quebec task force. A critical evaluation. Spine 1998;23:1043-49.

17. Gargan MF and Bannister GC. The rate of recovery following whiplash injury. Eur Spine J 1994;3: 162-4.

18. Kumar VG, Rea GL, Mervis LJ, McGregor JM. Cervical spondylotic myopathy: functional and radiographic long-term outcome after laminectomy and posterior fusion. Neurosurgery 1999;44:771-7.

19. Henderson CM, Hennessy RG, Shuey HM Jr, Shackelford EG. Posterior-lateral foramenectomy as an exclusive operative technique for cervical radiculopathy: a review of 846 consecutively operated cases. Neurosurgery 1983;13:504-12.

20. Young WF. Cervical spondylotic myopathy: a common cause of spinal cord dysfunction in older patients. Am Fam Physician 2000;62:1064-70.

21. Guidelines for the management of whiplash-associated disorders. Sydney, Australia: New South Wales Motor Accidents Authority; 2001. Available at: http://www.maa.nsw.gov.au/pdfs/whip_mgt_summary_ guide.pdf

22. Prodigy.nhs.uk [homepage on the Internet]. Newcastle upon Tyne: Sowerby Centre for Health Informatics at Newcastle; c2003 [cited 2003 Jun 6]. Available from: http://www.prodigy.nhs.uk.

23. Philadelphia panel evidence-based clinical practice guidelines on selected rehabilitation interventions for neck pain. Phys Ther 2001;81:1701-17.

24. AGS Panel on Persistent Pain in Older Persons. The management of persistent pain in older persons. J Am Geriatr Soc 2002;50(6 Suppl):S205-24.

25. Sanders S, Harden N, Benson SE, Vincente PJ. Clinical Practice Guidelines for chronic nonmalignant pain syndrome patients II: an evidencebased approach. J Back Musculoskel Rehabil 1999; 13:47-58.

26. American Pain Society. Principles of analgesic use in the treatment of acute pain and cancer pain. 4th ed. Glenview (IL): American Pain Society; 1999.

27. Guidelines for the initial evaluation of the adult patient with acute musculoskeletal symptoms. American College of Rheumatology Ad Hoc Committee on Clinical Guidelines. Arthritis Rheum 1996;39: $1-8$.

28. Practice guidelines for chronic pain management. A report by the American Society of Anesthesiologists Task Force on Pain Management, Chronic Pain Section. Anesthesiology 1997;86:995-1004.

29. Gore DR, Sepic SB, Gardner GM. Roentgenographic findings of the cervical spine in asymptomatic people. Spine 1986;11:521-24.

30. Boden SD, McCowin PR, Davis DO, Dina TS, Mark AS, Weisel S. Abnormal magnetic resonance scans of the cervical spine in asymptomatic subjects: a prospective investigation. J Bone Joint Surg Am 1990;72:1178-84.

31. Stiell IG, Wells GA, Vandemheen KL, et al. The Canadian c-spine rule for radiography in alert and stable trauma patients. JAMA 2001;286:1841-8.

32. Hoffman JR, Mower WR, Wolfson AB, Todd KH, Zucker MI. Validity of a set of clinical criteria to rule out injury to the cervical spine in patients with blunt trauma. N Engl J Med 2000;343:94-9.

33. Keats TE, Dalinka MK, Alazraki N, et al. Cervical spine trauma. American College of Radiology. ACR appropriateness criteria. Radiology 2000;215 Suppl: 243-6.

34. Seidenwurm D, Drayer BP, Anderson RE, Braffman B, Davis PC, Deck MD. Myelopathy. American College of Radiology appropriateness criteria. Radiology 2000;215 Suppl:495-505.

35. Fry SW, Seeff LB. Hepatotoxicity of analgesics and anti-inflammatory agents. Gastroenterol Clin North Am 1995;24:875-905.

36. Garcia-Rodriguez LA, Hernandez-Diaz S. The risk of upper gastrointestinal complications associated with nonsteroidal anti-inflammatory drugs, glucocorticoids, acetaminophen, and combinations of these agents. Arthritis Res 2001;3:98-101.

37. Deyo RA. Drug therapy for back pain: which drugs help which patients? Spine 1996;24:2840-50.

38. Browning R, Jackson JL, O'Malley PG. Cyclobenzaprine and back pain: a meta-analysis. Arch Intern Med 2001;161:1613-20.

39. Garvey TA, Marks MF, Weisel SW. A prospective randomized double-blind evaluation of trigger point 
injection therapy for low back pain. Spine 1989;14: 962-4.

40. Ferrante FM, Wilson SP, Iacoabo C, Orav EJ, Rocco AG, Lipson S. Clinical classification as a predictor of therapeutic outcome after cervical epidural steroid injection. Spine 1993;18:730-6.

41. Barnsley L, Lord SM, Wallis BJ, Bogduk N. Lack of effect of intraarticular corticosteroids for chronic pain in the cervical zygapophyseal joints. N Engl J Med 1994;330:1047-50.

42. Lord SM, Barnsley L, Wallis BJ, McDonald GJ, Bogduk N. Percutaneous radio-frequency neurotomy for chronic cervical zygapophyseal joint pain. N Engl J Med 1996;335:1721-6.

43. Binder A. Neck pain. Clin Evid 2002;8:232-34.

44. Magee DJ, Oborn-Barrett E, Turner S, Fenning N. A systematic overview of the effectiveness of physical therapy intervention on soft tissue neck injury following trauma. Physiother Canada 2000;52:111-30.

45. Hurwitz EL, Aker PD, Adams AH, Meeker WC, Shekelle PG. Manipulation and mobilization of the cervical spine: a systematic review of the literature. Spine 1996;21:1746-59.

46. Kjellman GV, Skargren EI, Oberg BE. A critical analysis of randomised clinical trials on neck pain and treatment efficacy. A review of the literature. Scand J Rehabil Med 1999;31:139-52.

47. Hoving JL, Gross AR, Gasner D, et al. A critical appraisal of review articles on the effectiveness of conservative treatment for neck pain. Spine 2001;26: 196-205.

48. Van der heijden GJ, Beurskens AJ, Koes BW, Assendelft WJ, de Vet HC, Bouter LM. The efficacy of traction for back and neck pain: a systematic, blinded review of randomized clinical trial methods. Phys Ther 1995;75:93-104. 